\title{
Concrete-Pictorial-Abstract Approach on Student's Motivation and Problem Solving Performance in Algebra
}

\author{
Heru Kurniawan ${ }^{1,2, *}$, Budiyono ${ }^{1}$, Sajidan $^{1}$, Siswandari $^{1}$ \\ ${ }^{1}$ Faculty of Teacher Training and Education, Sebelas Maret University, Indonesia \\ ${ }^{2}$ Department of Mathematics Education, Teacher Training and Education Faculty, Muhammadiyah University of Purworejo, Indonesia
}

Received March 10, 2020; Revised May 6, 2020; Accepted May 13, 2020

Copyright $₫ 2020$ by authors, all rights reserved. Authors agree that this article remains permanently open access under the terms of the Creative Commons Attribution License 4.0 International License

\begin{abstract}
This study aims to: 1) find out whether problem-solving performance in students who are subjected to the CPA approach is better than problem-solving performance in students who are subjected to conventional approaches, 2) find out whether learning motivation in students who are subjected to the CPA approach is better than learning motivation in students who are subjected to conventional approaches. The study was conducted on 7th-grade junior high school students in Purworejo Regency. This study was an experimental study involving 91 students in the experimental class and 96 students in the control class. The research instrument used observation sheets of student learning motivation and tests consisting of 20 multiple choice test items and 5 essay test items. The data analysis technique uses a paired sample T-test to see the improvement of problem-solving performance and independent sample T-test to see the difference in the influence of the CPA Approach with the conventional approach. The results showed that: 1) problem-solving performance in students who are subjected to the CPA approach is better than problem-solving performance in students who are subjected to conventional approaches, 2) motivation to learn in students who are subjected to the CPA approach is better than learning motivation in students who are subjected to conventional approaches. The results also show that the CPA Approach can encourage students to solve problems with nonstandard procedures.
\end{abstract}

Keywords Concrete-Pictorial-Abstract, Algebra, Problem-solving Performance, Motivation Performance

\section{Introduction}

Algebra is one of the mathematical material that studies about variables, coefficients, constants, symbols, and operations. However, learning algebra is not just learning about symbols, but more important is being able to apply algebraic knowledge to everyday life. Teachers need to remind that, algebra is the key to any success in mathematics at all and abstract algebra is critical to work in advanced mathematics' and the life and work opportunities that come with higher studies across a diverse range of occupations [1]. On the other side, success in algebra and courses beyond algebra are important in today's ever-changing technological society [2]. It was further explained that algebra is a gateway to later achievement, suggesting that being able to master algebraic principles leads to acquiring more advanced mathematical skills [3]. Some of the opinions above state that algebra is very important to study because it is related to other materials (geometry, arithmetic, calculus) and is very close to daily life.

Concept errors in algebra often occur, as a result, students will have difficulty or wrong when solving equations or even wrong when solving problems in the form of story problems. This error begins when students are not able to understand the concept of variables properly. The concept of 'variable' constitutes a basic constructional component in mathematics teaching in general and in algebra teaching in particular [4]. In some cases discovered by researchers during observations of learning in school, it appears that some of the fundamental mistakes made by students are as follows (1) $x+x=x^{2}$, (2) $x \cdot x=2 x$. Errors will be increasingly felt when faced with an equation that contains 2 variables, for example, $2 x+4 y=6 x y$. When the misconceptions and mistakes of the students are taken into account, it can be said that these may cause bigger 
problems in the further algebra topics [4]. Thus, understanding the concept of variables needs to be considered as the knowledge that students must have from the beginning of learning algebra. This error will be felt when faced with a more complex mathematical equation or a story problem that involves several operations at once. As a result, students experience difficulties in problem-solving activities.

Following the above, we need to learn that it can reduce the errors of algebraic concepts while making it easier for students when dealing with more complex problems, especially non-routine problems. Proper learning can bring up good algebraic thinking skills. The benefits of developing students' algebraic thinking can offer students a more meaningful conceptualization of algebra [5]. The ability to reason algebraically helps students think logically, identify patterns, form conclusions, construct arguments, and solve new and unfamiliar problems [6]. Following the above, algebraic thinking ability is very important for students to have for problem-solving activities.

One learning approach that can improve the understanding of algebraic concepts is through learning with a Concrete-Pictorial-Abstract (CPA) approach.

\section{CPA Approach vs Conventional Approach}

Cognitive psychologist Jerome Bruner felt that the goal of education should be intellectual development, as opposed to remote memorization of facts. In his study, he identified three stages of cognitive representation. These three stages of cognitive representation are enactive, iconic, symbolic. In practice, these three stages of cognitive representation can be applied to various subjects. The basic principle of inactive-iconic-symbolic is then developed further in the learning of mathematics into the Concrete-Pictorial-Abstract (CPA) step. CPA is based on the results of research from Jerome Bruner who states there are three steps (enactive, iconic, and symbolic) that can be taken by students to develop their mathematical abilities [7, 8]. Mathematical ability in that research is intended as the ability of students to understand mathematical language, skilled in using calculation techniques, turning problems into algebraic equations, and understanding number operations. Several previous studies stated that the CPA approach had a positive effect on increasing mathematical conceptual understanding [17]. Understanding of mathematical concepts includes the ability to identify concepts, distinguish one concept from another, and be able to link one concept to another. Other research also states that there is a significant difference in the levels of achievement in using Concrete-Pictorial-Abstract and Traditional approaches $[18,19]$. Learning achievements in that study talk more about the ability to solve mathematical problems, usually the problems solved are classified as routine problems that just need memorization and understanding.

In contrast to the results of the study above, in this study, the CPA approach is applied to non-routine problem solving to see students' problem-solving performance. This makes it possible to remember that non-routine problem solving requires a strong understanding of mathematical concepts so that it can link one concept to another so that it produces an appropriate solving strategy. Also, it can be seen further whether mathematical abilities also have a role in problem-solving activities.

On the one hand, it is desirable that understanding of the concept, increasing achievement, and increasing students' mathematical abilities through the CPA approach can influence student motivation. This is very possible because when students understand what they are learning, students will tend to be more motivated to do their work and learning tasks.

Based on the study of the study results above, opportunities arise for improvement and improvement in students' problem solving and motivation performance. It can be thought that the superiority of the CPA approach that can improve mathematical conceptual understanding and is better than traditional learning, can be used to improve problem-solving skills in algebraic material. This is quite possible considering that the algebra problem requires a good understanding of concepts so students can identify variables, coefficients, and constants presented in the given problem, especially the word problem. Understanding algebraic concepts built or constructed by students with the CPA approach can help students to apply them in other materials that involve algebraic concepts, such as geometry, calculus, and others.

CPA (Concrete-Pictorial-Abstract) is a learning approach that has been practiced in Singapore. This method in mathematics develops mathematical abilities and confidence without having to resort to memorizing procedures to pass tests for making mathematics more engaging and interesting. CPA learning practices can also be developed in other places according to the conditions and readiness of teachers and students. CPA in some literature is also known as Concrete-Representational-Abstract (CRA) or Concrete-Semiconcrete-Abstract (CSA). The adaptation of the relationship between Bruner's learning concepts and the CPA is shown in the table below [9].

Table 1. Learning Process and its corresponding teaching sequence

\begin{tabular}{|c|c|}
\hline Bruner Learning Process & CPA Teaching Action \\
\hline $\begin{array}{c}\text { Enactive } \\
\text { manipolves the physical } \\
\text { explore structure) }\end{array}$ & $\begin{array}{c}\text { Selection of concrete objects to } \\
\text { be manipulated and Facilitation } \\
\text { of the act of manipulating }\end{array}$ \\
\hline $\begin{array}{c}\text { Iconic } \\
\text { (use of images to represent the } \\
\text { concrete situation enacted in } \\
\text { the first stage) }\end{array}$ & $\begin{array}{c}\text { Facilitation of making } \\
\text { connections of iconic form and } \\
\text { mathematical idea }\end{array}$ \\
\hline $\begin{array}{c}\text { Symbolic } \\
\text { (use of words and symbols to } \\
\text { communicate) }\end{array}$ & $\begin{array}{c}\text { Facilitation of making a } \\
\text { connection to the abstract } \\
\text { mathematical symbol }\end{array}$ \\
\hline
\end{tabular}


Concrete presentation: At first pupils are first introduced to an idea or a skill by acting it out with real objects. Pictorial representation: Pupils have sufficiently understood the hands-on experiences performed and can now relate them to representations, such as a diagram or picture of the problem. Abstract: Pupils are now capable of representing problems by using mathematical notation. The learning steps with the CPA approach are as follows: 1) students interact with concrete objects to relate them to the concept of material, 2) transition from the way students work with images, diagrams, dots, and others as representations of concrete objects that were previously used, and 3) students are delivered to mathematical models abstractly by using numbers, symbols, notations, and other mathematical symbols $[10,11]$.

Table 2. CPA on Algebra Learning

\begin{tabular}{|c|c|c|}
\hline Concrete & Pictorial & Abstract \\
\hline & & \\
\hline
\end{tabular}

The advantage of learning with the CPA approach is that it can improve students' understanding of the concept of material because it is associated with real objects so that the cognitive structure that is formed can be used to learn further concepts or be used to solve more complex problems. The introduction of concrete objects that are associated with the material can reduce the errors of algebraic concepts, especially the understanding of variables. Examples of problem-solving with the CPA approach are as follows.

Problem: "There is a beverage processing factory. Every day the factory receives supplies of oranges that are transported from trucks and in units. One day the factory obtained supplies from 4 trucks and 5 oranges. What is the algebraic form of the problem?"

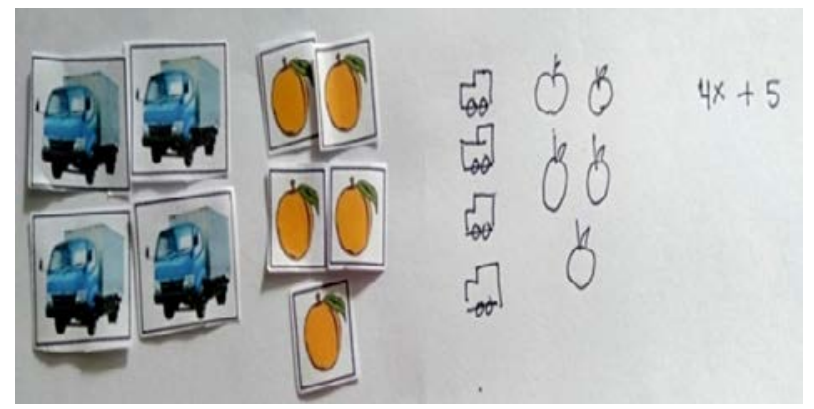

Figure 1. Solving Problem With CPA Approach

Learning with the CPA approach can improve student learning activities because it is directly involved with manipulating concrete objects, transforming them into pictorial forms, and presenting equations in the form of abstract mathematical models. Student interest and involvement in these learning activities will be able to increase student motivation. The CPA approach can reduce the errors of algebraic concepts, thus students can apply them to problem-solving activities. This is in line with the statement that CRA uses concrete materials to introduce the concept, then the students' design representations of concrete materials on paper, and eventually use abstract thought. This sequence of instructions has been used to teach problem-solving skills with integers [12].

The conventional approach in Indonesia generally uses lecture or expository learning. In conventional learning, learning activities are dominated by the teacher. Students become passive and not directly involved to create meaningful learning experiences. As a result, learning is more mechanistic, memorizing facts, and mimicking the completion procedures exemplified by the teacher. Specifically, on algebraic material, students are immediately introduced to the concepts of variables, coefficients, and constants without using the help of any teaching aids and just writing or notes on the board. The concept of algebra seems to be forced on students to memorize.

The conventional approach is certainly not following the abstract nature of algebra. Not all students can directly understand the concept of variables. This condition allows the emergence of errors in understanding the concept of algebra, especially when dealing with mathematical problems in the form of word problems.

To help students' difficulties and mistakes, it, therefore, needs to be scaffolded by the use of effective representations. In contrast to conventional approaches, Theoretically, when students use the CPA approach, they can build knowledge at each stage of learning towards a deeper understanding of the concepts being learned. Students are gradually introduced to the concept of algebra with the help of concrete objects that are slowly being converted into representation forms. Thus, information and knowledge can be internalized to a higher level in a more abstract form of algebra. In practice, students make it easy to associate and change statements in story problems in the form of algebraic equations. In this way, students will be more helped to solve the problems they face.

\section{Research Problem}

Based on the emergence of students' difficulties in learning mathematics, especially problem-solving in algebraic material, it is necessary to make improvements through appropriate learning, namely with the CPA approach. Therefore, the formulation of the problem in this study is whether the problem-solving performance and student learning motivation that is subjected to the CPA approach is better than the problem-solving performance and student learning motivation that are subjected to 
conventional approaches.

\section{Methods}

\subsection{Research Method}

This research is a quasi-experimental research with the randomized static group comparison design. The study was conducted from September to October 2019. The research population was all 7th-grade junior high school students in Purworejo Regency. Two groups are compared, namely groups that are subjected to the CPA approach (experimental group) and groups that are subjected to conventional approaches (control groups).

Both groups have the same characteristics, which are both taught by teachers who are certified as professional educators, using the same teaching material in the form of electronic school books published by the Ministry of National Education, and learning is carried out at the same time between 07.30 - 12.00 .

The equality of ability or achievement characteristics before treatment was given to each group and was further measured by an equilibrium test using an independent sample t-test.

\subsection{Population, Sample, and Sampling Techniques}

The population of this research is all 7th-grade students of Junior High School (SMP) in Purworejo Regency with an average age of 13 years. The number of SMP in Purworejo Regency is 43 schools. The sampling technique used is stratified cluster random sampling. All schools are categorized into 3 levels of the high, medium, and low achievers based on the results of the National Examination in 2019. In each category taken one school by drawing. Obtained SMP N 5, SMP N 12, and SMP N 13 as an experimental group and SMP N 3, SMP N 16, and SMP N 14 as a control group. In the experimental group, 91 students were consisting of 42 male students and 49 female students. In the control group, 96 students were consisting of 47 male students and 49 female students.

Table 3. Description of The Research Sample

\begin{tabular}{|c|c|c|c|c|c|c|}
\hline & \multicolumn{3}{|c|}{ Experimental Group } & \multicolumn{3}{c|}{ Control Group } \\
\hline & $\begin{array}{c}\text { SMP } \\
5\end{array}$ & $\begin{array}{c}\text { SMP } \\
12\end{array}$ & $\begin{array}{c}\text { SMP } \\
13\end{array}$ & $\begin{array}{c}\text { SMP } \\
3\end{array}$ & $\begin{array}{c}\text { SMP } \\
16\end{array}$ & $\begin{array}{c}\text { SMP } \\
14\end{array}$ \\
\hline Male & 14 & 16 & 12 & 15 & 18 & 14 \\
\hline Female & 17 & 14 & 18 & 17 & 14 & 18 \\
\hline Total & 31 & 30 & 30 & 32 & 32 & 32 \\
\hline
\end{tabular}

\subsection{Research Instrument}

The research instrument consisted of tests to measure problem-solving performance and observation sheets to see an increase in student motivation. The test is carried out for 80 minutes so that it uses 20 multiple choice test items and 5 test essay items. The validity of the test instrument was determined by the content validity through the assessment of 3 experts (expert judgment) to provide an assessment of their approval of the test.

Furthermore, the results of the assessment among 3 experts were calculated to produce an understanding between the experts of the test instrument. The calculation results from the three experts obtained an average of 3.6 (maximum score of 4.0). The reliability of the multiple-choice test with KR-21 obtained $\mathrm{r}_{11}=0.874$ and the essay test with the Alpha Cronbach obtained $\mathrm{r}_{11}=0.936$. Tests are given to both groups which are conducted at the end of the 5th learning meeting.

Motivational observation compiled to include 6 indicators, namely: 1) are interested in the learning process, 2) a strong desire to succeed, 3) do not give up easily when facing difficulties, 4) have a strong desire to achieve goals, 5) curiosity the big one, and 6) have the desire to face a challenging problem. Observation of student motivation is done in 5 meetings during learning by involving 2 observers in every class. Observation assessment is determined as a percentage by counting many students who display observational indicators compared to the total number of students.

Evaluation bias from each observer is anticipated in the Reflection Group Discussion activities consisting of practical teachers, 2 observers, and researchers. The observations from the observer are clarified together to obtain a more accurate observation data score to display indicators of motivation observation for each student.

\subsection{Data Analysis Technique}

The students' problem-solving test scores were then analyzed using an independent sample T-test to see the comparison of problem-solving performance in learning with CPA approaches and learning with conventional approaches. The results of observing learning motivation were analyzed descriptively by looking at the increase in the percentage of observations of each indicator at each learning meeting.

In the essay test, qualitative student work outcomes were observed. The results of student work will be assessed whether displaying solutions that are not procedural or unexpected. This is necessary to ensure that student problem-solving problems have emerged as a result of learning through the CPA approach.

\section{Result}

Analysis of the data in this study included observational data on learning motivation and the results of problem-solving tests on algebra material. The equilibrium 
test is carried out before the treatment is given to ensure that both classes have the same initial ability before the treatment is given. The balance test results with significance level $\alpha=5 \%$ obtained $\mathrm{t}_{\mathrm{obs}}=1,245<\mathrm{t}_{\mathrm{tab}}=1,973$. Thus $\mathrm{H}_{0}$ is accepted. So it was concluded that both classes have the same ability.

After giving treatment to both groups the following results were obtained.

\subsection{Students' Motivation Performance}

The results of research related to learning motivation are shown from observations of learning motivation during learning takes place in 5 meetings. At the end of each meeting, a reflection is conducted so that there is no bias in the evaluation of observations of motivation by observers.

The results of observing students' motivation are based on the following indicators: 1) are interested in the learning process, 2) a strong desire to succeed, 3) do not give up easily when facing difficulties, 4) have a strong desire to achieve goals, 5) curiosity the big one, and 6) have the desire to face a challenging problem. The indicators are presented in the form of observation sheets that are used by each observer to conduct observation activities. Each observation uses a new observation sheet so that the observation assessment is not affected by previous meetings.

The results of observations of students' learning, motivation can be seen in Table 4 below.

Table 4. Observation Results of Students' Learning Motivation on CPA Approaches

\begin{tabular}{|c|c|c|c|c|c|}
\hline \multirow{2}{*}{ Motivations' Indicator } & \multicolumn{5}{|c|}{ Learning meeting } \\
\cline { 2 - 6 } & M-1 & M-2 (\%) & M-3 & M-4 & M-5 \\
\hline Indicator 1 & $62 \%$ & $72 \%$ & $76 \%$ & $87 \%$ & $95 \%$ \\
\hline Indicator 2 & $59 \%$ & $64 \%$ & $77 \%$ & $85 \%$ & $96 \%$ \\
\hline Indicator 3 & $66 \%$ & $69 \%$ & $87 \%$ & $90 \%$ & $97 \%$ \\
\hline Indicator 4 & $60 \%$ & $71 \%$ & $78 \%$ & $90 \%$ & $96 \%$ \\
\hline Indicator 5 & $62 \%$ & $70 \%$ & $75 \%$ & $81 \%$ & $95 \%$ \\
\hline Indicator 6 & $67 \%$ & $74 \%$ & $78 \%$ & $87 \%$ & $97 \%$ \\
\hline Average & $63 \%$ & $70 \%$ & $78 \%$ & $87 \%$ & $96 \%$ \\
\hline Total Average & \multicolumn{5}{|c|}{$78 \%$} \\
\hline
\end{tabular}

Table 4 above shows that there was an increase in learning motivation at each meeting. An increase of between $7 \%-9 \%$, meaning that there is an increase in the number of students which shows an increase in learning motivation between 6-8 students per meeting. This increase in learning motivation appears to increase student learning activities. Even if we see an increase of only 6-8 students, at the end of the lesson it can be seen that $96 \%$ or 85 students (out of 91 students) show better learning activities.
Table 5. Observation Results of Students' Learning Motivation on Conventional Approaches

\begin{tabular}{|c|c|c|c|c|c|}
\hline \multirow{2}{*}{$\begin{array}{c}\text { Motivations' } \\
\text { Indicator }\end{array}$} & \multicolumn{5}{|c|}{ Learning meeting } \\
\cline { 2 - 6 } & $\mathrm{M}-1$ & $\mathrm{M}-2$ & $\mathrm{M}-3$ & $\mathrm{M}-4$ & $\mathrm{M}-5$ \\
\hline Indicator 1 & $49 \%$ & $55 \%$ & $60 \%$ & $67 \%$ & $77 \%$ \\
\hline Indicator 2 & $42 \%$ & $54 \%$ & $60 \%$ & $62 \%$ & $70 \%$ \\
\hline Indicator 3 & $45 \%$ & $54 \%$ & $61 \%$ & $72 \%$ & $88 \%$ \\
\hline Indicator 4 & $44 \%$ & $53 \%$ & $60 \%$ & $74 \%$ & $89 \%$ \\
\hline Indicator 5 & $48 \%$ & $55 \%$ & $63 \%$ & $69 \%$ & $75 \%$ \\
\hline Indicator 6 & $49 \%$ & $63 \%$ & $65 \%$ & $65 \%$ & $74 \%$ \\
\hline Average & $46 \%$ & $52 \%$ & $60 \%$ & $68 \%$ & $76 \%$ \\
\hline Total Average & & $50 \%$ \\
\hline
\end{tabular}

Table 5 above shows an increase between meetings between $6 \%-8 \%$ or 5-7 students. Even though it is not much different from the previous results, the difference in the pattern is seen in the percentage of motivation at the end of learning with an average of $76 \%$ or 72 students (out of 96 students).

The observations of student motivation as presented in the table above, have shown that there is an increase in student motivation after participating in learning with the CPA approach and the conventional approach

The results of observing the learning process in class also show the enthusiasm of students in participating in learning and solving problems/ assignments given. Student learning activities with the CPA approach can be seen in the following figure.
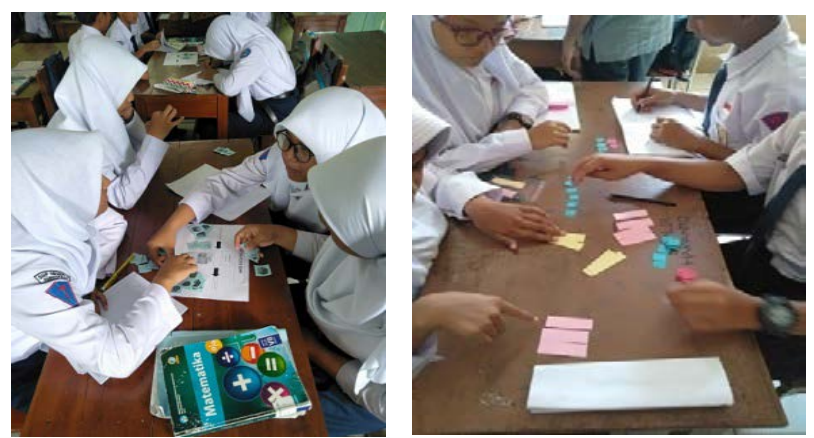

Figure 2. Learning with the CPA Approach

The picture above shows that students are enthusiastic/ motivated in completing tasks/ problems given during learning with the CPA approach. Students have shown a strong desire to complete the task by sharing ideas of completion in small group discussion activities. Students have also demonstrated proficiency in applying CPA stages by using concrete and pictorial objects that are available.

Observational data shows that students' learning motivation increases some of these images, reinforcing during learning with the CPA approach. 


\subsection{Students’ Problem Solving Performance}

A comparison of problem-solving performance in students subjected to the CPA approach and conventional approaches can be seen in the following table.

Table 6. Description of problem-solving post-test scores

\begin{tabular}{|c|c|c|c|c|c|}
\hline \multirow{2}{*}{ Class } & \multicolumn{5}{|c|}{ Score post-test } \\
\cline { 2 - 6 } & $\mathrm{n}$ & $\bar{X}$ & Sd & Max & Min \\
\hline Experimental Group & 91 & 59,868 & 15,143 & 93 & 27 \\
\hline Control Group & 96 & 43,420 & 16,027 & 78 & 7 \\
\hline
\end{tabular}

Based on the above results, a different average test is then performed with the T-test. A summary of the t-test can be seen in the table below.

Table 7. Summary of PCA-Conventional T-test results

\begin{tabular}{|c|c|c|c|c|c|c|c|}
\hline Class & $\mathrm{N}$ & $\bar{X}$ & $\mathrm{Sd}$ & $\mathrm{Sp}$ & $\mathrm{t}_{\mathrm{obs}}$ & $\mathrm{t}_{\text {tab }}$ & Decision \\
\hline $\begin{array}{c}\text { Exp } \\
\text { Class }\end{array}$ & 91 & 59,868 & 15,143 & & & & \\
\hline $\begin{array}{c}\text { Control } \\
\text { Class }\end{array}$ & 96 & 43,420 & 16,027 & 2850 & 28,774 & 1,973 & $\begin{array}{c}\mathrm{H}_{0} \\
\text { Rejected }\end{array}$ \\
\hline
\end{tabular}

Comparison of post-test scores in the experimental group and the control group with significance level $\alpha=5 \%$ obtained $\mathrm{t}_{\mathrm{obs}}=28,774>1,973=\mathrm{t}_{\mathrm{tab}}$, so the decision $\mathrm{H}_{0}$ was taken. Thus the conclusion of the problem-solving performance of students who are subjected to the CPA approach is better than the problem-solving performance of students who are subjected to conventional approaches.

Improved problem-solving performance is also shown by the results of the performance after the problem description. The results of the problem-solving description show that students have come up with various/ non-procedural solving procedures. The following are some of the results of solving the problem in the problem given below.

"Melia makes some cakes. He sells 3/5 of the cakes in the morning and the remaining $1 / 4$ of the cakes in the afternoon. If he sells 100 cakes in the morning more than in the afternoon, then how many cakes does he make?"

\section{Solution 1}

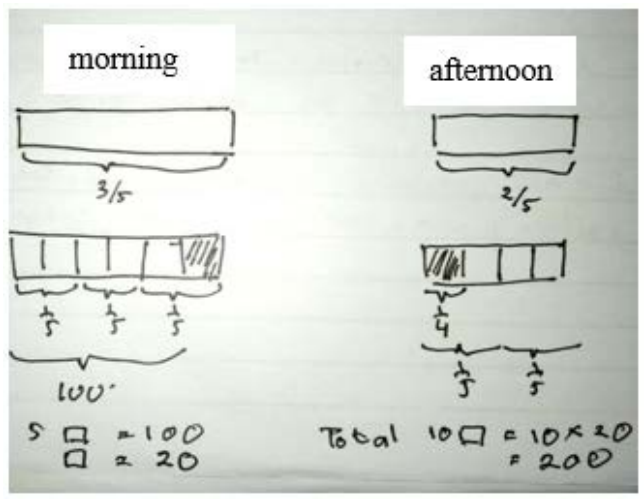

Figure 3. Solution 1
The above settlement uses the application of the CPA by carrying out the problem-solving procedure by dividing the cake into morning and evening conditions. Then, the calculated difference in cakes sold in the morning with 100 cakes in the afternoon. Furthermore, the cake difference is divided into several units ( 5 units are obtained), so that each unit is equal to 100: $5=20$ cakes. Finally, the cake is taken into account as a whole into 10 units until $10 \times 20=200$ cakes are obtained.

\section{Solution 2}

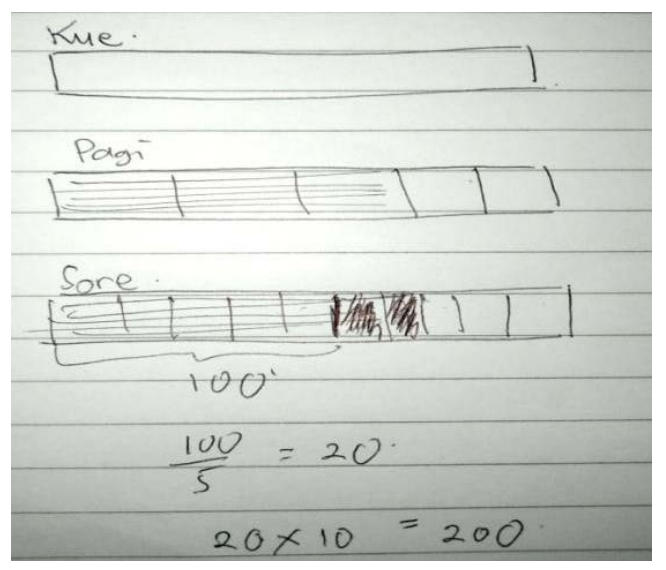

Figure 4. Solution 2

The settlement above is done by taking the cake into the whole bar. Furthermore, the sale of cakes is calculated in the morning as much as $3 / 5$ so that the whole bar is divided into 5 parts with 3 shaded parts. The rest of the cake that is not shaded is the cake sold in the afternoon. Because the cake is sold $1 / 4$ in the afternoon and the bar is divided into 4 parts with 1 shaded section.

It is known that the difference between the sales of cakes in the morning and evening is 100 cakes, so the sales of cakes in the morning are divided into several parts where 1 part has the same value as the sales in the afternoon. Obtained 5 parts equal to 100 cakes, so that 1 part is equal to 20 . Then it is calculated that there are 10 parts, so that obtained $10 \times 20=200$ cakes.

\section{Solution 3}

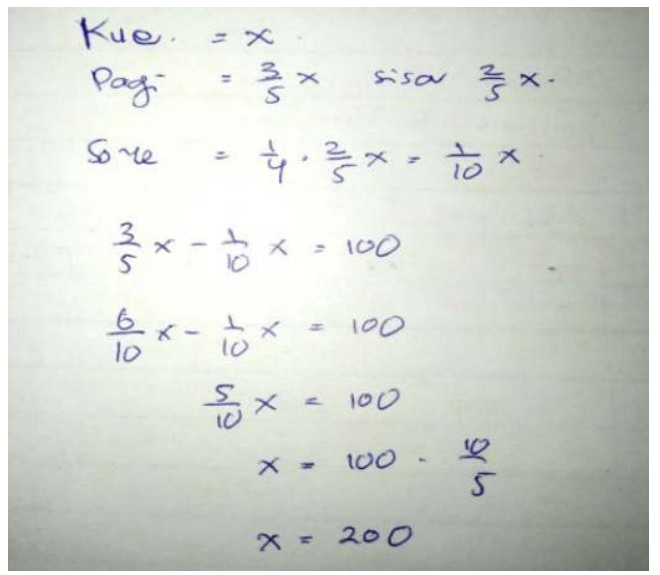

Figure 5. Solution 3 
The above solution uses an algebraic calculation by assuming the number of cookies that is $\mathrm{x}$. Furthermore, it is determined that $3 / 5$ parts are sold in the morning so that the remaining $2 / 5$ parts are sold in the afternoon. Because sales in the afternoon are $1 / 4$ parts, multiplied by $2 / 5$ the remaining parts are obtained 1/10. Furthermore, the difference between morning and evening sales is calculated at 100 cakes, so that it is obtained $\mathrm{x}=200$.

These three forms of resolution have shown that students can solve problems with unusual procedures, as shown in solutions 1 and 2. In general, the various forms of solving indicate that the application of the CPA approach can encourage students to use their learning experiences so that they can be applied in solving the problem in another form.

\section{Discussion}

The results of the study above show that: 1) Students' learning motivation that is subjected to CPA approach is better than students' learning motivation that is subjected to conventional approaches, and 2) Problem Solving performance on students who are subjected to the CPA approach is better than Problem Solving performance on students who are subjected to the conventional approach.

Concerning learning motivation, the average percentage of achievement assessment of observations in groups subjected to the CPA approach scored $78 \%$ compared to $60 \%$ in groups subjected to conventional approaches. This can be seen from the enthusiasm of students during the learning process using the CPA approach, which seems better than the conventional approach. During learning with the CPA approach students feel challenged and feel they have a good understanding of the concept of algebra. This happens because students in understanding the concept of algebra (variables, coefficients, constants) are carried out in stages from concrete objects converted to representation and finally to abstract form. As a result of this, students do not experience difficulties or misconceptions when facing a given problem, ease in understanding the concept of god that causes an increase in student motivation.

Unlike the conventional approach, students are more struggling with memorizing facts so that misconception is more likely to occur. Students are repeatedly wrong in constructing algebraic equations of a given problem. As a result, students tend to be lazy to think and ignore the overall learning because they feel unable to understand the material provided by the teacher. As a result, student learning motivation, although there is an increase, did not increase significantly. This is consistent with the opinion that says The CRA (Concrete-Representational-Abstract) approach has also been employed to aid students with hearing disabilities to learn mathematics [7].

The CPA approach provides self-confidence and a positive influence for students so as to bring high learning motivation. This is indicated by students' confidence when solving challenging problems and a strong desire to solve the given problem. This is consistent with reports that students show improvement in fluency and confidence by CRA instruction [13]. These results are also the same as the findings that using CRA gives a positive effect on low achievers [14].

This increase in learning motivation is accompanied by an increase in students' problem-solving performance. Students with good motivation can understand algebraic concepts well and apply them to solving the given problem. Such students understand that one of the goals of learning mathematics is to be able to solve problems in various contexts. This is in line with the statement that the CPA has a positive attitude toward success in Math and the usefulness of Math. They are doubtful in Math Anxiety, motivation, and confidence in learning Math [15].

The mean score on the group that was subjected to the CPA approach was 59.86 compared to 43.42 in the control group. The mean score on the group with the CPA approach seems to be still quite low. However, this can still be understood considering that the application of the CPA approach is a learning activity that is still newly accepted by students. On the other hand, the provision of mathematical problems that require non-procedural problem solving is not yet commonly known and given to students. Therefore, this CPA approach is very potential to help students improve their learning outcomes in an exemplary manner, only that there is a need to make efforts to get used to by the teacher, both in the form of learning activities and giving mathematical problems.

Student problem-solving performance on algebra material with the CPA approach is better than the performance of solving with conventional approaches. This happens because, in the CPA approach, students can understand concepts and algebraic arithmetic operations of concrete objects to minimize the occurrence of conceptual errors. Students are able to distinguish variables, constants, and coefficients appropriately so that they can be used for problem-solving. Students correctly understand algebraic operations through the manipulation of concrete objects/teaching aids that are available so that they are able to transform them into pictorial and abstract forms. Thus, students do not experience difficulties when meeting the equation and solving algebraic forms. This is different from conventional approaches. In this approach, the concept of algebra is directly given in the abstract form, so that misconceptions, especially in the operation of algebraic forms, often occur. As a result, course mistakes occur in problem-solving activities. This is consistent with the results of research which states that the research result showed that achievement of student mathematics representation with the CPA teaching and learning approach is better than students with conventional teaching and learning [16]. 


\section{Conclusions}

Based on the results of the study above, it shows that 1) student motivation has increased during learning with the CPA approach, 2) the performance of problem-solving in students subjected to learning with the CPA approach is better than the performance of problem-solving in students subjected to learning with conventional approaches, and 3) students' problem-solving performance has improved after being subjected to learning by the CPA approach.

The results of content analysis of student work on the description test show that students can solve problems using non-standard solving procedures. Besides, several alternative solutions have emerged. This shows that the learning experience with the CPA approach gives the influence of high motivation so that it raises a strong desire and unyielding nature of students to try various alternative solutions to the problem until the right solution is found.

Based on this, the CPA approach is very appropriate to be applied in algebra learning. CPA approach can lead students to have an understanding of algebraic concepts correctly so that with this understanding students can solve various problems presented in various forms. It is interesting to study further about the effectiveness of the CPA approach on material other than algebra.

\section{Acknowledgment}

The results of this study are part of a dissertation in the FKIP UNS Education Science doctoral study program. Thank you to the promoters who have guided so that this research can be carried out well.

\section{REFERENCES}

[1] V. Katz. Stages in the history of algebra with implications for teaching. Educational Studies in Mathematics, 66, 185-201, 2007.

[2] C. Hill. When traditional won't do: experiences from a "lower-level" mathematics classroom. The Clearing House, 83: 239-243, 2010. DOI: 0.1080/00098655.2010.484439

[3] National Mathematics Advisory Panel. Foundations for success: The final report of the national mathematics advisory panel. U.S. Department of Education: Washington, DC, 2008.

[4] O. Sahin and Y. Soylu. Mistakes and misconceptions of elementary school students about the concept of "variable. Procedia Social and Behavioral Sciences. 15, 3322-3327, 2011.

[5] G. Booker and W. Windsor. Developing algebraic thinking: using problem-solving to build from number and geometry in the primary school to the ideas that underpin algebra in high school and beyond. Procedia Social and Behavioral Sciences 8, 411-419, 2010.

[6] T. Hudson. Algebra readiness through deeper learning in middle school: how teachers can empower students to achieve with confidence. DreamBox Learning, Inc.,1-16, 2015.

[7] Y. H. Leong, W. K. Ho, L. P. Cheng. Concrete-Pictorial-Abstract: surveying its origins and charting its future. The Mathematics Educator, Vol. 16, No. 1, 1-19, 2015

[8] K. Y. Wong. Effective mathematics lessons through an eclectic Singapore approach: yearbook 2015. Association of Mathematical Educator. Singapore: World Scientific Publishing, 2015

[9] Ch. S. Hui, L. Ng. Hoe, K. Ph. Lee. Teaching and learning with Concrete-Pictorial-Abstract sequence-a proposed model. The Mathematics Educator. Vol. 17. No. 1 \& 2, 1 28, 2017

[10] E. T. Cooper. Using virtual manipulatives with pre-service mathematics teachers to create representational models. International Journal for Technology in Mathematics Education. Vol 19, No 3, 2012

[11] E. P. Hafiziani, Misnarti, D. S. Ria. Influence of concrete-pictorial-abstract (CPA) approach towards the enhancement of the mathematical connection ability of elementary school students. EduHumaniora: Jurnal Pendidikan Dasar. Vol. 10 No.2, 61-71, 2018

[12] J. S. Cease-Cook. The effects of the concrete-representational-abstract sequence of instruction on solving equations using inverse operations with high school students with mild intellectual disability. Dissertation: The University of North Carolina at Charlotte, 2013

[13] M. M. Flores. Using Concrete-Representation-Abstract sequence to teacher subtraction with regrouping to students at risk for failure, remedial and special education. 31(3), 195-207, 2010.

[14] F. M. Butler, S. P. Miller, K. Crehan, B. Babbit, \& T. Pierce. Fraction instruction for students with mathematics disabilities: comparing two teaching sequences. Learning Disabilities Research and Practice, 18, 99-111, 2003.

[15] N .R. Salingay, D. A. Tan. Concrete-Pictorial-Abstract approach on student's attitude and performance in mathematics. International Journal of Scientific \& Technology Research, Vol. 7, Issue 5, page 90-111, 2018

[16] E. P. Hafizianii. The Influence of Concrete Pictorial Abstract (CPA) approach to the mathematical representation ability achievement of the pre-service teachers at elementary school. International Journal of Education and Research, Vol. 3, No. 6, 113-126, 2015.

[17] Purwadi, Sudiarta, and Suparna. The Effect of Concrete-Pictorial-Abstract Strategy toward Students' Mathematical Conceptual Understanding and Mathematical Representation on Fractions. International Journal of Instruction Vol.12, No.1 pp. 1113-112, 2019

[18] Hafiziane, Putri, and Ria. Influence Of 
Concrete-Pictorial-Abstract (CPA) Approach Towards The Enhancement Of Mathematical Connection Ability Of Elementary School Students. Jurnal Pendidikan Dasar Vl. 10 No. 2, Page 61- 71, 2018

[19] Isip, J.L. Comparison between Traditional Approach and Concrete-Pictorial-Abstract (CPA) Approach in Teaching College Algebra. International Journal of Scientific \& Engineering Research Volume 9, Issue 9, September-2018. Page: 1290-1294, 2018 